\title{
Outcome and medium-term functional results of anterior rectopexy for rectocele repair
}

\author{
M. J. W. Bogaerts-Samama • S. R. C. Driessen • \\ E. Jenninga • J. B. V. M. Delemarre • J. B. Trimbos • \\ M. E. Westerweel
}

Received: 4 March 2013 / Accepted: 6 October 2014 / Published online: 14 October 2014

(C) Springer-Verlag Berlin Heidelberg 2014

\begin{abstract}
This retrospective observational study was designed to assess patients' satisfaction after anterior rectopexy, with or without sacropexy, for treatment of symptomatic rectocele in a group of women with anterior rectoceles. Between February 1995 and March 2011, all female patients who underwent an anterior rectopexy for large (>grade 2) anterior rectocele were included in the study. Preoperatively, the rectocele was assessed at rectovaginal examination and a defecography was performed. Rectovaginal examination was repeated in all patients 6 weeks postoperatively and a control defecography was performed 6 months after surgery. Followup included a standard telephone questionnaire and chart review. The surgical techniques used were anterior rectopexy (ARP; $n=21)$ and ARP + sacropexy (ARP + SP; $n=20)$. Mean age of the study group was 60 years (range $=36-77$ ) and median parity was 2.6 (range $=0-8)$. Median follow-up from anterior $\mathrm{ARP} \pm \mathrm{SP}$ to functional assessment was 40 months (range $=4-83$ ). In both groups, two of the initial main clinical symptoms (discomfort due to feeling of prolapse and outlet obstruction) improved significantly $(p<0.05)$. Anterior rectopexy (ARP $\pm \mathrm{SP})$ restores durable anatomic support and functional improvement in female patients with a large (>grade 2) anterior rectocele.
\end{abstract}

Keywords Rectocele · Anterior rectopexy · Genital prolapse · Pelvic organ prolapse $\cdot$ Sacrocolpopexy

Hans Delemarre passed away on 22 December 2005. Esther Jenninga passed away on 15 December 2009.

M. J. W. Bogaerts-Samama

Sint Franciscus Gasthuis, Rotterdam, The Netherlands

S. R. C. Driessen - E. Jenninga • J. B. V. M. Delemarre •

J. B. Trimbos $\cdot$ M. E. Westerweel $(\bowtie)$

Leiden University Medical Center, PO Box 9600, 2300 RC Leiden,

The Netherlands

e-mail: M.E.Westerweel@lumc.nl

\section{Introduction}

Rectocele is defined as a protrusion of the anterior rectal wall and the posterior vaginal wall into the lumen of the vagina [1-4]. Pelvic organ prolapse is a common condition in female adults $[5,6]$. Clinical symptoms include constipation, dyspareunia and pelvic discomfort (e.g. awareness of a bulging mass, a bearing-down sensation and pelvic pressure). Also, chronic urge to defecate and feelings of incomplete defecation, occasionally requiring manual expression to complete evacuation, are common complaints, as well as lower abdominal and back pain and incontinence of gas or faeces [1, 7-10].

Rectoceles are present in up to $80 \%$ of asymptomatic women and many symptoms of a rectocele are similar to the symptoms of other pelvic floor disorders of the posterior compartment (e.g. rectal intussusception, enterocele, anismus or spastic pelvic floor syndrome) [1]. Therefore, it should be confirmed that pelvic organ prolapse symptoms are due to a rectocele by eliminating other causes of the differential diagnosis $[1,10]$.

Therapeutic options for rectocele are pessaries and management of constipation by dietetic measures and laxatives $[10,11]$. When conventional treatment fails, surgery is required. The optimal rectocele repair technique remains a subject of debate as recurrent prolapse and incontinence is common, of which a large proportion requires reoperation (29.2 \%) [12]. Postoperative dyspareunia, constipation and (partial) incontinence have been reported as well [1,9]. This is a retrospective cohort study that evaluates the outcome of anterior rectopexy with or without sacropexy, in population of women with anterior rectoceles.

\section{Materials and methods}

Between February 1995 and March 2011, a consecutive series of female patients with a large (>grade 2) and 
symptomatic anterior rectocele and without a large (>grade 2) cystocele or enterocele, underwent an anterior rectopexy. All patients were seen by a gynaecologist (MEW) and a colorectal surgeon (JBD), working together as a team at the Pelvic Floor Centre of the LUMC. Preoperatively, the rectocele was assessed with the Baden-Walker Halfway System at rectovaginal examination and a defecography was performed.

Dynamic defecography was performed by an established protocol by Delemarre et al. [13] with oral contrast to visualize the small bowel, vaginal contrast to visualize the anatomic position and movements of the vagina and bladder as well as rectal contrast, recorded on video and described by one reviewer (MEW).

At the postoperative visit, rectovaginal examination was repeated by the same team in all patients. A control defecography was performed in most patients postoperatively to document anatomical repair.

Information was distracted from the hospital files and data were collected from non-validated questionnaires on patients' presenting and postoperative symptoms (de novo or persisting) - noted as main complaint—overall comparison, main symptom improvement and overall patient satisfaction. At the start of this research, validated questionnaires were not commonly used in our surgical department; the authors of this article decided not to change this questionnaire for this specific patient group.

Main symptom improvement was graded as worse, no change, improvement or completely improved. Overall comparison was graded as worse, no change, improvement or major improvement. Extent of patient satisfaction was graded as satisfied, neutral or not satisfied. All patients had the opportunity to mention persisting or new onset symptoms in the questionnaire. Exemption of a hospital's Ethics Committee approval was granted in view of the cheer registration design of the study (not WMO obligated; WMO is Dutch law on Medical Research).

\section{Surgical procedures}

Indications for anterior rectopexy strictly consisted of one or more of the following features: rectocele more than $2 \mathrm{~cm}$ at defecography, high-positioned anterior rectocele (at physical examination and defecography), limited vaginal width (at physical examination) and/or a history of complaints and dyspareunia [14]. To explain this more clearly, in patients with a low positioned or smaller than $2 \mathrm{~cm}$ anterior rectocele (ARC), without an enterocele or invagination, with absence of defecation symptoms and without prior surgery, vaginal approach was preferred. Posterior colporrhaphy is a preferable treatment in cases with a small rectocele. At the time of inclusion, transvaginal mesh was not an available option in our centre. It is common practice that ARC is performed concomitant with other procedures for pelvic organ prolapse. In case of such a combination, we have selected patients in our series of ARP with a large ARC (>grade 2) and an asymptomatic (<grade 2) vault prolapse as we regarded the clinical symptoms as caused by the ARC. Assessment of the size and grade of these prolapse were made by the aforementioned pelvic floor team on the basis of symptoms, pelvic examination and defecography findings.

The ARP was extended to a sacrocolpopexy (SP), in case of an asymptomatic small (<grade 2) concomitant vault prolapse, uterine descensus or as prevention of an impending pelvic organ prolapse. Distinction between a concomitant vault prolapse and enterocele was mainly based on defecography. An impending prolapse was estimated during surgery, after the rectocele correction was performed, by rectovaginal examination and traction on the vaginal vault or cervix.

At the time of induction of anaesthesia, cefuroxime $(1500 \mathrm{mg})$ and metronidazole $(500 \mathrm{mg})$ were administered intravenously. With the patient in the lithotomy Trendelenburg position, the abdomen was opened with a midline or transverse (Maylard) incision. The anterior rectal wall was mobilized from the promontory downwards by opening the peritoneum right out of the meso-rectum. The rectovaginal septum was dissected minimally until a correct suspension of the rectum could be provided for. This was checked by rectovaginal examination during the procedure. The lateral ligaments were preserved as much as possible and the right hypogastric nerve was identified and preserved as well. Fixation of the anterior rectal wall to the sacrum, just below the promontory, was performed using a polypropylene mesh of $9 \times 3 \mathrm{~cm}$, because of its low infection rate and high adhesive potential (Marlex ${ }^{\circledR}$ or Gynemesh ${ }^{\circledR}$ ). Nine non-absorbable sutures, three rows of three, were placed to secure the mesh to the anterior rectal wall, $10-12 \mathrm{~cm}$ from the distal margin of the rectum, and three were used to secure it to the sacrum. A polytetrafluoroethylene inverted Y-shaped mesh (Gore-tex ${ }^{\circledR}$ ) was used to fix the apex of the vagina (or the vaginal posterior side, at the level of the fornix posterior in patients with a previous hysterectomy) to the sacrum, to anatomically restore the vaginal axis. Four non-absorbable sutures, placed above the level of the uterine arteries, were used to secure the mesh to the vaginal apex and three were placed to secure this mesh to the sacrum or to a Marlex mesh in case of minimal space. The peritoneum was reefed by a continuously running resorbable suture, to seal the area of reconstruction and to further prevent the formation of an enterocele. All procedures were performed by the same team of surgeons (MEW and JBD). 


\section{Statistical analysis}

Statistical analysis was performed using SPSS 17.0 statistical software. The paired sample $t$ test was used to compare the data. $P<0.05$ was considered to be statistically significant.

\section{Results}

Of the study group of 41 consecutive female patients, the mean age was 60 years (range $=36-77$ ) and median parity 2.6 (range $=0-8$ ). Median follow-up time from anterior rectopexy to functional assessment was 40 months (range $=$ 4-83). The performed surgical techniques were anterior rectopexy (ARP; $n=21)$ and ARP+sacropexy $(\mathrm{ARP}+\mathrm{SP}$; $n=20$ ). The mean operation time was $173 \mathrm{~min}$, with a median total blood loss of $234 \mathrm{ml}$. Median hospital stay was 9.8 days (range $=7-18$ days). There were no intra-operative complications observed and no blood transfusions were required. There were two postoperative urinary tract infections, no wound infections and no postoperative deaths. No late complications, including-mesh related problems, were encountered. The preoperative and postoperative findings of defecography are shown in Table 1. The preoperative defecography showed rectocele $>$ grade 2 in all 41 patients, and the postoperative defecography revealed a persistent rectocele grade 1 in 9 patients. None of the patients had a recurrent rectocele $>$ grade 2 .

At follow-up, 38 of the 41 patients answered the questionnaire about the main symptoms and satisfaction postoperatively. Patients were asked if they still had complaints of pelvic organ prolapse, noted as a main clinical symptom, or if there was improvement of these complaints, and if they were satisfied with the overall results of the operation.

The initial main clinical symptom improved significantly. Complaints of pelvic organ prolapse feeling decreased from 25 to 0 patients (61 to $0 \%$ ), outlet obstruction from 10 to 2 patients ( 25 to $5 \%$ ). Table 2 shows the pre- and postoperative main complaints. There were no correlations between the preoperative or postoperative grade of prolapse and main complaint, postoperative satisfaction or symptomatic improvement.

Overall, in $42 \%$ of the cases, there was an improvement of the main symptom; $3 \%$ of the patients had no complaints at all

Table 1 Findings of defecography

\begin{tabular}{lll}
\hline Findings & Preoperative & Postoperative \\
\hline $\begin{array}{l}\text { Rectocele } \\
>\text { Grade 2 }\end{array}$ & $41(100 \%)$ & \\
$\leq$ Grade 1 & $0(0 \%)$ & $0(0 \%)$ \\
\hline
\end{tabular}

In nine patients, no defecography was performed postoperatively
Table 2 Main symptoms preoperatively and postoperatively

\begin{tabular}{lll}
\hline Main symptom & Preoperative & Postoperative \\
\hline Pelvic organ prolapse feeling & $25(61 \%)$ & $0(0 \%)^{* *}$ \\
Outlet obstruction & $10(25 \%)$ & $2(5 \%)^{*}$ \\
Incontinence & $2(5 \%)$ & $4(11 \%)$ \\
Imperative defecation urge & $3(7 \%)$ & $3(8 \%)$ \\
Dyspareunia & $1(2 \%)$ & $0(0 \%)$ \\
None & $0(0 \%)$ & $29(76 \%)^{* *}$ \\
\hline
\end{tabular}

Postoperative total response $n=38$

$* P<0.05$

$* * P<0.001$

postoperatively. Table 3 shows that $87 \%$ of the patients were satisfied with the overall results of the operation. Only one patient was not satisfied after her surgery. She was in need of a second operation (an anterior colporrhaphy) within 6 months after her anterior rectopexy, because of a cystocele grade 2 .

\section{Discussion}

Pelvic organ prolapse has an impact on a woman's daily activities and negatively affects her quality of life, although it rarely results in severe morbidity or mortality [15]. With an ageing population, the incidence of and demand for repair of pelvic organ prolapse is increasing and therefore, it remains an actual and highly relevant topic in gynaecological practice [16]. It may be difficult to diagnose rectocele at clinical examination, and many of the symptoms of a rectocele overlap other pelvic floor disorders, such as rectal intussusception, enterocele, anismus or spastic pelvic floor syndrome; therefore, defecography is needed to visualize the rectocele [1-3].

The ARP described in this study was introduced to treat symptomatic prolapse and to minimize recurrence rates and de novo outlet obstructions. The ARP, the current surgical approach in presented patients, is minimally destructive by mobilizing only the anterior rectal wall, preserving the lateral ligaments, minimally opening the rectovaginal septum, and completely preserving the anatomy on the left side of the rectum.

The results of this study confirm that ARP can considerably decrease the symptoms of pelvic organ prolapse: in the present study, all patients had a rectocele at

Table 3 Extent of patient satisfaction

\begin{tabular}{ll}
\hline & $\begin{array}{l}\text { Patient satisfaction } \\
\text { postoperatively }\end{array}$ \\
\hline Satisfied & $33(87 \%)$ \\
Neutral & $4(10 \%)$ \\
Not satisfied & $1(3 \%)$ \\
\hline
\end{tabular}


defecography preoperatively and improvement of the rectocele was observed in all cases that had a postoperative defecography (78\%). Wren et al. [17] found that in women planned for pelvic organ prolapse repair, greater preoperative optimism is associated with better postoperative results; whether or not this was the case in the present study is unknown as it was not the subject of the analysis of data.

In contrast to our findings, Vermeulen et al. [1] described deterioration of symptoms after treatment of symptomatic rectoceles by a modified anterolateral rectopexy. A common side effect was worsening or de novo dyspareunia, with rates as high as $44 \%[1,4,18]$. Also, in the study of Vermeulen et al., coital incontinence was found to have deteriorated in $37 \%$, a symptom with high impact on the women's quality of life $[1,18,19]$. These adverse effects were not reported in the present study.

The authors recognize the limitations of the current study due to its retrospective design and to the relatively small number of patients. On the other hand, the study addresses an issue that has been given very little attention to in the literature. Furthermore, all patients were physically examined by the same team of surgeons (MEW and JBD), improving the reliability of the findings. The great loss of two of the authors of this study (EJ and JBD) resulted in a delay of completion of this study. And for this reason, the Baden-Walker Halfway System was used to objectify pelvic organ prolapse, instead of the POP-Q system.

In conclusion, rectocele-associated symptoms have a large impact on social life and daily activities. Treatment of symptomatic rectocele by ARP \pm SP provides good anatomical and functional outcomes. In this study, there were no persistent or new onset complaints mentioned. Most published studies show improvement for the symptom of vaginal protrusion and improvement in the need for digitation whilst the prevalence of postoperative symptoms remains high. Other symptom resolution or the development of new symptoms remains unpredictable and variable. It is difficult to compare this operation with others because of different inclusion and exclusion criteria, different surgical techniques, the low preoperative prevalence of dyspareunia and the lack of a validated questionnaire. Therefore, further prospective randomized clinical trials have to be undertaken to compare functional outcome and patients' satisfaction after different surgical techniques in the treatment of symptomatic rectoceles.

Informed consent All procedures followed were in accordance with the ethical standards of the responsible committee on human experimentation (institutional and national) and with the Helsinki Declaration of 1975 , as revised in 2000. Informed consent was obtained from all patients prior to surgery.
Conflict of interest All the authors declare no conflict of interest.

\section{References}

1. Vermeulen J, Lange JF, Sikkenk AC, Van der Harst E (2005) Anterolateral rectopexy for correction of rectoceles leads to good anatomical but poor functional results. Tech Coloproctol 9:35-41

2. López A, Anzén B, Mellgran A, Nilsson BY, Zetterström J, Holmström B (2001) Durability of success after rectocele repair. Int Urogynecol J 12:97-103

3. Beck DE, Allen NL (2010) Rectocele. Clin Colon Rectal Surg 23(2): 90-98

4. Oom DM, Gosselink MP, van Wijk JJ, van Dijl VR, Schouten WR (2008) Rectocele repair by anterolateral rectopexie: long-term functional outcome. Colorectal Dis 10(9):925-930

5. Milani R, Salvatore S, Soligo M, Pifarotti P, Meschia M, Cortese M (2005) Functional and anatomical outcome of anterior and posterior vaginal prolapse repair with prolene mesh. BJOG: Int J Obstet Gynaecol 112:107-111

6. Shull B (1999) Pelvic organ prolapse: anterior, superior, and posterior vaginal segment defects. Am J Obstet Gynecol 181(1):6-11

7. Oom DM, Van Dijl VR, Gosslink MP, Van Wijk JJ, Schouten WR (2007) Enterocele repair by abdominal obliteration of the pelvic inlet: long-term outcome on obstructed defaecation and symptoms of pelvic discomfort. Colorectal Dis 9(9):845-850

8. Nieminen K, Hiltunen KM, Laitinen J, Oksala J, Heinonen PK (2004) Transanal of vaginal approach to rectocele repair: a prospective, randomized pilot study. Dis Colon Rectum 47:1636-1642

9. Jean F, Tanneau Y, Le Blanc-Louvry I, Leroi AM, Denis P, Michot F (2002) Treatment of enterocele by abdominal colporectosacropexyefficacy on pelvic pressure. Colorectal Dis 4(5):321-325

10. Cundiff GW, Fenner D (2004) Evaluation and treatment of women with rectocele: focus on associated defecatory and sexual disfunction. Obstet Gynecol 104(6):1403-1421

11. de Tayrac R, Picone O (2006) A 2-year anatomical and functional assessment of transvaginal rectocele repair using a polypropylene mesh. Int Urogynecol J 17:100-105

12. Olsen AL, Smith VJ, Bergstrom JO, Colling JC, Clark AL (1997) Epidemiology of surgically managed pelvic organ prolapse and urinary incontinence. Obstet Gynecol 89:501-506

13. Delemarre JB, Kruyt RH, Doornbos J, Buyze-Westerweel M, Baptist Trimbos J, Hermans J, Gooszen HG (1994) Anterior rectocele: assessment with radiographic defecography, dynamic magnetic resonance imaging, and physical examination. Dis Colon Rectum 37(3):249-259

14. Wiersma TG, Mulder CJ, Reeders JW, Tytgat GN, Van Waes PF (1994) Dynamic rectal examination (defecography). Baillieres Clin Gastroenterol 8:729-741

15. Ellerkmann RM, Cundiff GW, Melick CF, Nihira MA, Leffler K, Bent AE (2001) Correlation of symptoms with location and severity of pelvic organ prolapse. Am J Obstet Gynecol 185:1332-1337

16. Bot-Robin V, Lucot JP, Giraudet G, Rubod C, Cosson M (2012) Use of vaginal mesh for pelvic organ prolapse repair: a literature review. Gynecol Surg 9:3-15

17. Wren PA, Janz NK, FitzGerarld MP, Barber MD, Burgio KL, Cundiff GW, Nygaard IE, Zyczynski HM, Gao X (2008) Optimism in women undergoing abdominal sacrocolpopexy for pelvic organ prolapse. J Am Coll Surg 207:240-245

18. Baessler K (2011) Do we need meshes in pelvic floor reconstruction? World J Urol. 2011 Nov 16

19. Fayyad AM, North C, Reid FM, Smith AR (2011) Prospective study of anterior transobturator mesh kit (prolift) for the management of recurrent anterior vaginal wall prolapse. Int Urogynecol J 22:157163 